\title{
ESTE ANIMAL QUE SOY
}

se va de largo

y en sus costillas reconoce el pelaje manchado

- por la sangre

la saliva

el vómito-

la violencia que posee las ganas del desgarre

- propio a todo el género humano-

Este animal que soy se viste de conciencia femenina mientras lava los platos

Soy perversa

calculadora fría mentirosa hipócrita me distiendo sobre todos

los planos de las interpretaciones

más allá de lo que yo misma me quiera hacer creer

Esto no es una letanía a mis defectos

no soy Werther extasiado y en el lodo

no recuerdo los pasos de memoria

y me declaro el espacio donde todos los ciclos terminan

la conciencia débil y accesible

el cuerpo en renta

el departamento de muestra que nadie jamás posee

lugar que se viste para otros

sin la necesidad de ser habitado

Todo esto es ficción

padezco bovarismo desde mis primeros años

Soy mitómana e hipocondriaca (nadienuncatocomicuerpoinfantilenlaregaderanimellamomentirosanuncabeseaunamujerniseolvidarondemínuncanadiemecorriódesucasayvaciómiscosasenunabolsadecamisetanitodasmisposesionescabíanahímipadrenuncaseprendiófuegonidejedeiraverloalhospitalporlamiradayelmiembroacechantedemiprimosobremismuslosnuncanadiemellamointeresadanimalagradecidamimadrenuncasearrepin- 
tiónidescargoelrencorfrustradodesusañossobremínuncasentíelrechazonituveganasdesentarmeenelpisodelbañodecualquierbarallorarnuncalegritéaalguienniintentéempastillarmeporsentirqueerasuficientenuncasentíquefuerasuficiente)

Todo esto es ficción y me reduzco a mi palabra a esta adopción de discursos gastados poetamalditaconfesionalposmodernasuicida

[que omite el acto inaugural y romántico de la muerte No hay nada más romántico que autonegarse romántico NOSOYROMÁNTICA

Me avergüenzo de esta mutilación de mis miembros (de esa adopción de cuerpos) por la ansiedad constante de caricias Rehúyo a los colores cálidos (con el foco fundido del baño se siente frío aún en un cuarto

[1leno de vapor el sesgo sensorial de la luz) cavo hoyos en la tierra con las dos manos y me raspo las entrañas con una cuchara hasta quedar vacía antes del desayuno y con la nubosidad de un animal tejo una danza de algodón en mi ombligo y uso mi sexo como el mejor paliativo a mis dudas sobre el lenguaje (con su inaptitud de indeterminar la nada) que hacen vomitar a mis amigos soy un cuerpo Yo la peor de todas Soy un animal que metamorfoseó cada uno de sus miembros en una lengua y desde ahí se nombra 
Se prohíbe su reproducción total o parcial por cualquier medio, incluido electrónico, sin permiso previo y por escrito de los editores. 